\title{
Preschool and higher education in the context of digitalization: problem statement
}

\author{
Larisa Zakharova ${ }^{1 *}$, Yelena Andrianova ${ }^{1}$, Marina Silakova ${ }^{2}$, and Yekaterina Subbotina ${ }^{1}$ \\ ${ }^{1}$ Ulyanovsk State Pedagogical University named after I.N. Ulyanov, Department of Preschool and \\ Primary General Education, Ulyanovsk, Russia \\ ${ }^{2}$ Ulyanovsk State Pedagogical University named after I.N. Ulyanov, Department of Psychology, \\ Ulyanovsk, Russia
}

\begin{abstract}
Sociocultural transformation of society, its digitalization dictate certain requirements to the system of education. Adaptation of education processes both in kindergartens and universities is related with readiness of teachers for implementation of digital technologies into education process. The significance of their use in education is accompanied by numerous questions regarding elimination of negative influence of digital content on a forming developing person, on their rational and reasonable application at early stages of social and personal development of preschool children. The conceptual field of pedagogy is supplemented by new categories: digital education, digital education environment, digital competence. This article presents results of teachers' surveying on the issue of readiness to designing information environment and attitude to the digital technologies implemented into education. On the one hand, the teachers highlighted advantages of the applied information technologies: individual education, possibility to master the program by preschool children and to consolidate knowledge and skills in the case of prolonged absence from studies, time saving, mobility and flexibility of education. On the other hand, the teachers mentioned the main drawbacks of the use of digital technologies: possible harm for health of children, inability of full development of speech, communication skills, development of gaming activity. The main problems preventing active use of modern technologies are comprised of low digital competence of university graduates and working teachers; age features of preschool children, which do not allow to study material without assistance by adults; the lack of opportunities of pupil's parents to actively participate in educational activity of preschool entity.
\end{abstract}

Keywords: Digitalization of education, tutors, preschool education, education environment.

\section{Introduction}

The digitalization process cardinally modifies the education format, it is related not only with conversion of information into digital format but also with infrastructural,

\footnotetext{
*Corresponding author: ulseagull@mail.ru
} 
organizational, behavioral constituents of overall education of all education entities of various levels [1].

Analysis of studies in the field of digital education in universities demonstrates that the new education format, joint actions of teacher and students are characterized by obvious advantages: availability, continuity, individual training, opportunity of choice. Therefore, in developed countries, the online education is defined not as a trend but as the main option $[2,3]$. At the same time, there are certain disadvantages affecting education quality: low interactivity, doubtful control of learned material, primitivity of competences [4]. Digitalization of education requires from students higher responsibility for quality of their education, since the significance of attendance of traditional classes becomes lower [5].

This work is aimed at analysis of teacher's readiness to use the modern information technologies in working with preschool children, creation of information educational environment of preschool entity. The research objective implies studying opportunities of digital education in training teachers and its potential in the system of preschool education. The novelty of the research is in attempt to comprehend the problems of preschool education in terms of society challenges related with digitalization, in attempt to find the ways to overcome the difficulties related with this process, to understand the issues of teacher's training requiring for formation of information competence.

Implementation of digital technologies at all levels of education, on the one hand, provides continuity of educational activity under the conditions of forced lockdown, and on the other hand, raises a number of questions [6]. The influence of digital education on the level of mastering educational material by students and formation of general cultural and subject competencies has not been analyzed in details. And if the knowledge component can be measured by practically oriented assignments (case method, designing), then the level of communicative skills, ability and readiness to work in a team, organization of emotional background of interaction, provision of pedagogical support of child development remain in question.

Preschool teachers face the objective of creation of educational environment capable to help a child to integrate into fast changing high-tech world of knowledge and information with accounting for integrated approach: science-technology-innovation. However, the modern Russian system of preschool education is inadequate to the society requirements [7]. For instance, Finland and Sweden already provide studying digital competence in the programs of preschool education. It assumes not only the use of the technologies by teachers during classes but also familiarization of children with media elements, manipulation with media files and operation with equipment. This is a challenge to professional skills and efficiency of teachers, who are not sometimes ready for it [8]. The task of teachers is to adapt a modern child to the life in digital world, to critically refer to the technologies and to use their advantages. The main teaching tool in this aspect should be digital play using dedicated applications and software [9]. Herewith, it is important to maintain emotional and psychic welfare of a child, pattern and content of education in accordance with age and individual abilities and capabilities, health safety, satisfaction of a family and child with services of preschool entity [10, 11].

While analyzing the work of teachers in Taiwan kindergartens, it has been concluded that the attitude of teachers to integration of Internet into education of young children can be measured using four factors: self-efficiency (estimation of skills by teachers), the use of educational applications (selection, inclusion of various applications into work, development of own applications), the pleasures of Internet (the more positive is the teacher's attitude to the technologies, the more readily they are mastered and applied in the work and this interest is fostered to the children), and professional support (opportunity to use Internet for consultations, experience exchange, establishment of cooperation with colleagues) [12]. 


\section{Methods}

The applied methods included surveying, quantitative and qualitative analysis of the obtained results and initial sources. Twenty six teachers participated in the research, both young and with the working experience of more than 20 years, representatives of urban and rural kindergartens.

\section{Results}

$92.3 \%$ of teachers understand the role and significance of mixed education and define it as the combination of traditional forms of education with elements of electronic education, where special information technologies are used, as the education that combines teaching with teacher's participation and online teaching, that is, this is electronic online distance learning.

Only $11.5 \%$ of teachers could determine the advantages of mixed training, among which the first position was occupied by time saving: opportunity not to spare time for travelling. Other advantages include getting advanced training when convenient, involvement into work of more participants during consultations and meetings, safety for health, children's interest in this form of education, mastering new technologies by teacher, opportunity for children to study program in the case of illness.

Among the disadvantages the respondents mention the absence of personal contact, the difficulties of children in studying the material $(11.5 \%)$, no opportunity to develop speech and communication with peers $(23 \%)$. Almost all teachers expressed concern that such teaching would lead to serious problems with health.

In addition, the teachers highlight technical difficulties in the use of elements of digital learning, organization of distance work. They mention that technical equipment and support are required, and not all participants in distance learning can be efficiently involved in this process due to material conditions (no PC, notebook, high-speed Internet), up to impossibility to obtain such education. These difficulties were mentioned especially often by teachers from rural areas. In addition, the teachers reasonably mention that the distance learning of preschool children requires for participation of parents, if the parents are unable to spend sufficient time for child's learning, then the level of knowledge comprehension will be extremely low.

$84.5 \%$ of teachers state insufficient level of professional competence in the field of modern information technologies. Nevertheless, the teachers actively use the information technologies in their practice. More often the teachers make presentations (69\%), use video clips for learning $(38.4 \%)$, use computer games $(11.5 \%)$, participate in video conferences with colleagues $(30.7 \%)$ and parents $(7.7 \%)$. Some teachers make and edit videos, organize parents' surveying at kindergarten website, take advanced learning courses. At the same time, only one teacher produced author's video film. The teachers' opinion about reasonability of distance learning is representative. Overwhelming majority of teachers are strongly against (73\%) and allow the mixed education only in urgent cases, when traditional learning is impossible. However, they are steadily interested in understanding of digitalization and necessity of their own deeper technological qualification.

\section{Discussion}

Analysis of the performed surveying, monitoring students during distance learning, analysis of teachers' opinion have demonstrated that digitalization in preschool learning creates many questions. The teachers and the parents face the dilemma: either harmful for health or 
beneficial for knowledge [7]. Restrictions, especially at early stages, of communication with parents, interaction with people decrease the level of development and emotional intelligence of preschool children [13].

The issues of formation of information culture of preschool children become significant in the system of preschool education. In the system of higher education, important is the principle of not increase in the amount of information knowledge but of implementation of certain algorithm promoting mastering and transfer of knowledge by means of internal and external tools of cognition [5]. Any strategy of university development assumes solution to training graduates of required qualification, including with necessary digital competences of present time; this presupposes application of mixed models of education [4, 14].

Both experienced and young preschool teachers experience difficulties with integration of digital technologies into learning process. And here it should be agreed with the opinion of researchers concerning expansion of list of competences of university graduates and working teachers. They should provide development of digital skills, ethical and legal, environmental knowledge, bilingual training.

The study performed in Serbia concerning the readiness of teachers to use ICT in kindergarten demonstrates that the teachers face the same difficulties: complications in mastering the technologies, necessity for material and technical resources, aged teachers are slower and more reluctantly learn the new methods. However, the teachers mention the readiness to learn, estimate high the efficiency of application of software in working with preschool children in three areas: acquisition of new knowledge, consolidation of learned material, free time. Development of technological competence of teachers should be continuous in the frames of formal (special disciplines in teachers colleges, programs of advanced training) and nonformal (seminars, master classes) education [15].

For correct and substantiated application of digital environment in preschool entities, the issue of development of digital competence of students and teachers is especially important. It is characterized by ability to design and to use content by means of digital technologies applying computer programming, graphical techniques, computer graphics, etc., information search and exchange, communication with other trainees [16]. Modern graduates, passing the school of distance learning, have some skills in the field of designing information education environment, though, it is insufficient for creation of efficient education content.

\section{Conclusion}

Digital transformation of society is directly reflected at all levels of education system, it will continue to be stronger over time. Both students and preschool teachers seemed to be unprepared for such processes. Despite the questions of decreasing negative influence of digital technologies on developing personality, reasonability of their application at early stages of social and personal development, the authors have determined the sources for further psychological and pedagogical studies, modernization of established traditions in education, ability of teachers to adapt rapidly for new realities.

\section{References}

1. P.N. Bilenko, V.I. Blinov, M.V. Dulinov, Ye.Yu. Yesenina, A.M. Kondakov, I.S.

Sergeyev, The didactic concept of digital vocational education and training (Izdatel'stvo "Pero", Moskva, 2020)

2. H. Kentnor, Curriculum and Teaching Dialogue, 17(1-2), 20 (2015) 
3. J.E. Seaman, I.E. Allen, Grade Increase: Tracking Distance Education in the United States (Babson Survey Research Group, 2018)

4. A.A. Klimov, Ye.Yu. Zarechkin, V.P. Kupriyanovskiy, Modern information technologies and IT education, 15, 468-476 (2019)

5. V.Sh. Maslennikova, Bulletin of Chuvash State Pedagogical University named after I.Ya. Yakovleva, 2(102), 134-140 (2019)

6. Ye.A. Balygina, Social relations, 1(32), 6-16 (2020)

7. I.I. Komarova, Modern preschool education. Theory and practice, 8(90), 16-25 (2018). https://doi.org/24411/1997-2018-10032

8. P. Mertala, M. Koivula, Journal of Early Childhood Education Research, 9(1), 1-5 (2020)

9. L. Marklund, Journal of Early Childhood Education Research, 9(1), 171-193 (2020)

10. T.N. Boguslavskaya, Detskiy sad: teoriya i praktika, 10, 16-27 (2016)

11. N.V. Lomova, A.A. Khuseynova, Socio-cultural problems of education development in the context of project management, 373-379 (2018)

12. Pi-Chun Hsu, I-Hsiung Chang, Ru-Si Chen, SAGE Open, 10(1) (2020). https://doi.org/10.1177/2158244020914390

13. M.M. Silakova, L.M. Zakharova, Journal of Psychology and Cognition, 3(1), 249-253 (2018). https://doi.org/10.35841/psychology-cognition.3.1.6-10

14. J. Neronia, C. Meijs, Learning and Individual Differences, 73, 1-7 (2019)

15. S. Veličković, L. Stošić, International Journal of Cognitive Research in Science, Engineering and Education, 4(1), 23-30 (2016)

16. N.P. Petrova, G.A. Bondareva, Mir nauki, kultury i obrazovaniya, 5(78), 353-355 (2019) 